Revista de Estudios Histórico-Jurídicos

[Sección historia del derecho chileno]

XLII (Valparaíso, Chile, 2020)

[pp. 579-601]

\title{
LAS VARIACIONES DEL RÉGIMEN PRESIDENCIAL CHILENO DURANTE LA VIGENCIA DE LA CONSTITUCIÓN DE 1925
}

\author{
[Variations chilean presidential regime during the term of the \\ Constitution of 1925]
}

\author{
Felipe Meléndez Ávila* \\ Universidad Mayor, Chile
}

\section{RESUMEN}

El presente trabajo aborda el régimen de gobierno practicado durante la vigencia de la Constitución chilena de 1925 . Se mostrará que las prerrogativas presidenciales establecidas en la norma constitucional fueron relativizadas con éxito por el Congreso Nacional, por medio de reformas legales, prácticas políticas y legislativas, y la interpretación de preceptos constitucionales, morigerando en términos relevantes la forma de gobierno presidencialista hasta finales de la década de 1960. Para probar tal cuestión, se recurrirá a la revisión y análisis tanto de la normativa y doctrina constitucional como de las principales posiciones historiográficas respecto a este periodo.

\section{Palabras Clave}

Forma de gobierno - presidencialismo - Constitución de 1925 - reforma de 1970 - prácticas políticas.

\section{Abstract}

The present work deals with the government regime practiced during the validity of the Chilean Constitution of 1925 . It will be shown that the presidential prerogatives established in the constitutional norm were successfully relativized by the National Congress. Through legal reforms, political and legislative practices, and the interpretation of constitutional precepts, dying in relevant terms the form of presidential government until the end of the 1960s. In order to prove this issue, the revision and analysis of both the constitutional norms and doctrines and the main historiographical positions will be used to this period.

\section{KeY Words}

Form of government - presidentialism - Constitution of 1925 - reform of 1970 political practices.

Recibido el 8 de enero de 2020 y aceptado el 15 de abril de 2020

* Abogado. Licenciado en Ciencias Jurídicas y Sociales y Doctor en Derecho, por la Facultad de Derecho de la Universidad de Chile. Director de la Escuela y profesor de Derecho Constitucional, en la Facultad de Humanidades de la Universidad Mayor, Santiago de Chile. Correo electrónico: felipemelendezavila@gmail.com. 


\section{INTRODUCCIÓN}

Existe la visión compartida en un sector importante, tanto en la doctrina constitucional ${ }^{1}$ como en la historiografía chilena ${ }^{2}$ que, desde el segundo mandato de Arturo Alessandri Palma, iniciado a finales de 1932, hasta el quiebre institucional del 11 de septiembre 1973, habría primado sin mayores alteraciones la forma de gobierno presidencialista. Esta ha sido caracterizada por el predominio institucional del Ejecutivo respecto de los demás poderes públicos, particularmente, sobre el Congreso Nacional. Las razones para esgrimir tal cuestión se encontrarían, principalmente, en la idea que, con la promulgación y posterior entrada en vigencia de la Carta de 1925, se habría puesto término definitivamente a las bases constitucionales que sirvieron de sustento para la interpretación parlamentarista de la Carta precedente, la Constitución de 1833.

Si profundizamos en las motivaciones de los constituyentes de 1925, efectivamente puede apreciarse que existió la clara voluntad, principalmente en Alessandri Palma, de terminar con el régimen político anterior. Así se eliminarían, por una parte, aquellas instituciones que directa e indirectamente entregaban al Congreso Nacional mayores prerrogativas para controlar el actuar del Ejecutivo, como lo eran las leyes constitucionales o periódicas y las interpelaciones y los votos de censura. Y, por otra, se entregarían al Presidente de la República mayores prerrogativas frente al Congreso, propiciando una mayor separación de poderes y funciones de éste con aquel ${ }^{3}$.

Aun así, a diferencia de lo acaecido durante la vigencia de la Carta de 1833, reformas como las llevadas a cabo en 1943 y en 1970 fueron en la línea de ir entregando cada vez mayores prerrogativas al Presidente de la República en desmedro del Congreso Nacional. ¿Por qué se potenciaron aún más las prerrogativas del Ejecutivo en una Constitución que habría resuelto los embates provocados por la práctica parlamentaria del régimen de gobierno?

Al respecto, existen trabajos que dan cuenta del rol de los partidos políticos en las variaciones de la forma de gobierno durante este periodo ${ }^{4}$. Incluso, uno

\footnotetext{
${ }^{1}$ Cea Egaña, José Luis, Derecho constitucional chileno (3a ed., Santiago, Ediciones UC, 2015), I, p. 61; RUIZ-TAgLE, Pablo, Cinco repúblicas y una tradición. Constitucionalismo chileno comparado (Santiago, Lom, 2016), p. 2; Verdugo, Mario y Pfeffer, Emilio, La Constitución de 1925, en Verdugo, Mario, Pfeffer, Emilio y Nogueira, Humberto, Derecho constitucional (2a ed., Santiago, Editorial Jurídica de Chile, 2005), I, p. 24.

${ }^{2}$ Campos Harriet, Fernando, Historia constitucional de Chile. Las instituciones sociales y políticas (4a ed., Santiago Editorial Jurídica de Chile, 1969), p. 347; EyzAGuirre, Jaime, Historia de las instituciones políticas y sociales de Chile (19a ed., Santiago, Editorial Universitaria, 2011), pp. 196-197; HeISE, Julio, Historia de Chile. El periodo parlamentario 1861-1925. Tomo I: Fundamentos histórico-culturales del parlamentarismo chileno (Santiago, Editorial Jurídica de Chile, 1974), pp. 294-300.

${ }^{3}$ Ministerio del Interior, Actas oficiales de las sesiones celebradas por la Comisión y Subcomisiones encargadas del proyecto de nueva Constitución Política de la Repuiblica (Santiago, Imprenta Universitaria, 1925), p. 8. Véase también: CORREA, Sofía, Los procesos constituyentes en la historia de Chile. Lecciones para el presente, en Estudios Públicos, 137 (2015), p. 58.

${ }^{4} \mathrm{Al}$ respecto, véase: BRAVO LiRA, Bernardino, Régimen de gobierno y partidos politicos en Chile 1924-1973 (Santiago, Editorial Jurídica de Chile, 1978); Vial CorREA, Gonzalo, Decadencia,
} 
de ellos plantea abiertamente la interrogante de si el régimen de gobierno habría sido parlamentario o presidencial ${ }^{5}$. Sin embargo, éstos no logran sistematizar en todo su alcance los mecanismos invocados por el Congreso Nacional que terminaron siendo decisivos en la relativización del presidencialismo promovido por el texto de 1925 .

A continuación, abordaremos el diseño normativo inicial establecido en la Carta de 1925, caracterizado por un presidencialismo fuerte, destinado a dotar de autonomía al Ejecutivo en la conducción del gobierno pero, al mismo tiempo, de influencia en la función legislativa. Posteriormente, se argumentará cómo reformas legales, prácticas políticas y legislativas, y la interpretación de preceptos constitucionales, relativizaron en términos relevantes la forma de gobierno, tornándola más equilibrada. Finalmente, se analizará cómo a través de la reforma constitucional de 1970 promovida por Eduardo Frei Montalva, estos mecanismos terminaron siendo bloqueados normativamente, constituyendo un régimen presidencial reforzado, el cual terminó yendo más allá de los lineamientos del texto de 1925 original. De esta manera, el presente trabajo realizará un análisis del régimen de gobierno practicado durante la vigencia de la Constitución de 1925 desde la perspectiva del derecho constitucional en perspectiva histórica.

\section{EL DISEÑO NORMATIVO INICIAL DEL RÉGIMEN PRESIDENCIALISTA} EN EL TEXTO DE 1925

La Constitución de 1925 se caracterizó por fortalecer en términos relevantes al Presidente de la República, respecto de los demás poderes públicos. Por medio de él, se procuró el establecimiento de un régimen representativo de carácter presidencial $^{6}$. Existe acuerdo entre los constitucionalistas del periodo en el carácter desequilibrado del régimen de gobierno adoptado por los constituyentes de $1925^{7}$. Esto debido a que éste se alejó de la clásica concepción doctrinaria del gobierno presidencial norteamericano, estructurado en la Constitución de Filadelfia ${ }^{8}$, puesto que apostó, más bien, hacia una confusión de poderes, con un claro predominio del poder Ejecutivo por sobre el Congreso Nacional, procurando terminar con las bases constitucionales que permitieron la práctica del parlamentarismo en Chile?

consenso y unidad nacional en 1973, en Dimensiones Históricas de Chile, 1 (1984), p. 153; IBÁN̄EZ SANTA María, Adolfo, Herido en el ala: Estado, oligarquías y subdesarrollo. Chile 1924-1960 (Santiago, Editorial Biblioteca Americana, 2003); BraHm, Enrique, ¿Volver a la Constitución de 1925? Una propuesta sin fundamento histórico, en Revista Chilena de Derecho, 46 (2019), pp. 79-97; Faúndez, Julio, Democratización, desarrollo y legalidad. Chile, 1831-1973 (Santiago, Ediciones Universidad Diego Portales, 2011), p. 126.

${ }^{5}$ Brahm, Enrique; Bertelsen, Raúl; Amunátegui, Andrés, Régimen de gobierno en Chile: ¿presidencialismo o parlamentarismo? $1925-1973$ (Santiago, Editorial Jurídica de Chile, 2002).

${ }^{6}$ Amunátegui, Gabriel, Manual de derecho constitucional (Santiago, Editorial Jurídica de Chile, 1950), pp. 274-275.

${ }^{7}$ Véase al respecto en: Amunátegui, Gabriel, cit (n. 6), p. 275; Bernaschina Mario, Manual de derecho constitucional (2a ed., Santiago, Editorial Jurídica de Chile, 1955), p. 61.

${ }^{8}$ Amunátegui, Gabriel, cit. (n. 6), p. 275.

${ }^{9} \mathrm{Al}$ respecto, véase, entre otros: CAmpos Harriet, Fernando, cit. (n. 2), p. 348; Heise, Julio, 
Este enfoque desequilibrado del régimen de gobierno no fue propio de Chile, sino que se enmarcó dentro de las formas de gobierno practicadas y/o consagradas en la región, susceptibles de ser caracterizadas bajo el rótulo de presidencialismo latinoamericano ${ }^{10}$.

En efecto, se estableció la incompatibilidad entre las funciones de senador y diputado con las de ministro de Estado, uno de los principales rasgos que habían permitido catalogar como p a r l a m e n t a r i a la forma de gobierno bajo la Constitución de 1833. Asimismo, se suprimieron las leyes periódicas ${ }^{11}$, con la sola excepción de la ley de presupuesto que, por su naturaleza, necesitaba de dicha periodicidad, pero estableciendo un mecanismo de sanción tácito en caso de que éste no fuese aprobado antes del plazo en que debía comenzar a regir, con la finalidad de bloquear su uso como mecanismo de presión por parte del Congreso Nacional ${ }^{12}$.

A los cambios anteriormente señalados, se sumaron otros establecidos en favor del Ejecutivo, al tiempo que se mantuvieron prerrogativas que venían de la Carta reformada de 1833 , con miras a mejorar su posición institucional en relación a los demás poderes públicos, principalmente, sobre el Congreso Nacional. En efecto, en cuanto a las que se aprecia continuidad destaca el veto suspensivo, potestad presente desde la reforma constitucional de $1893^{13}$. Asimismo, la prerrogativa de convocatoria a sesiones extraordinarias, que antes requería del acuerdo del Consejo de Estado ${ }^{14}$ y que quedó entregada al Presidente y al Congreso, a través del presidente del Senado, separadamente ${ }^{15}$.

Por su parte, en cuanto a las prerrogativas en que se aprecia un cambio relevante, destacan la introducción del sistema de urgencias y la iniciativa legislativa exclusiva del Ejecutivo. El mecanismo de urgencias tuvo por objeto evitar la excesiva demora del debate parlamentario. De esta manera, el Presidente de la República quedaba autorizado para declarar la urgencia en el despacho de un pro-

cit. (n. 2), p. 441; Carrasco Delgado, Sergio, Génesis y vigencia de los textos constitucionales chilenos ( $3^{\mathrm{a}}$ ed., Santiago, Editorial Jurídica de Chile, 2002), p. 161.

${ }^{10}$ Respecto a las categorías de regímenes presidenciales en América Latina, véase: NogueIrA, Humberto, La tipología de gobiernos presidencialistas de América Latina y gobiernos semipresidenciales en Europa, en Estudios Constitucionales, 2 (2017), pp. 17 ss.; CARPIZO, Jorge, Concepto de democracia y sistema de gobierno en América Latina (2a reimp., México D.F., UnAM, 2009), pp. 176 ss.; MELÉNDEZ, Felipe, La forma de gobierno en el Chile actual: un caso de presidencialismo latinoamericano equilibrado, en Revista Republicana, 26 (2019), pp. 23-26.

${ }^{11}$ Las leyes periódicas consistían en normas de rango legal caracterizadas por tener una duración definida, que, dependiendo de la materia, podían ser de un año, como en el caso de la ley de presupuesto, o de dieciocho meses, en el caso de la que autorizaba al cobro de contribuciones. Previo a su vencimiento, se requería nuevamente de la discusión y aprobación del Congreso Nacional, ya que si éstas no eran despachadas oportunamente, tras el cumplimiento del plazo perdían su vigencia. Al respecto, véase: HeISE, Julio, cit. (n. 2), pp. 28-29.

${ }^{12}$ Amunátegui, Gabriel, cit. (n. 6), p. 276.

${ }^{13}$ Ley de reforma constitucional No 43, 26 de febrero de 1892. Véase: VAlenCia Avaria, Luis, Anales de la República (2ª ed., Santiago, Editorial Andrés Bello, 1986), p. 210.

${ }^{14}$ Éste órgano fue reforzado a favor del Congreso después de la reforma de 1874 . Véase: Valencia Avaria, Luis, Anales, cit. (n. 13), p. 210.

${ }^{15}$ Constitución Política de la República de Chile, 18 de septiembre de 1925, artículo 57. 
yecto, correspondiendo, en todo caso, la calificación del grado de dicha solicitud de urgencia al criterio de cada Cámara. Aun cuando el precepto constitucional establecía un plazo de 30 días para discutir el proyecto, los reglamentos de cada Cámara lo redujeron ${ }^{16}$. En efecto, en ellos se consagraban las diversas clases de urgencias que podían recibir los proyectos de ley, también conocidos como "calificación de las urgencias", entre los cuales se encontraba la simple urgencia, la suma urgencia y la extrema urgencia o discusión inmediata ${ }^{17}$.

La segunda prerrogativa a destacar, es la iniciativa exclusiva del Presidente de la República, establecida con ocasión de la regulación de la ley de presupuesto, particularmente, en lo que dice relación con los aumentos o la alteración de las entradas establecidas en ella ${ }^{18}$. Sin embargo, esta norma no fue impedimento para que el Congreso pudiese interferir en prerrogativas exclusivas del Ejecutivo, lo que se reflejó en la aprobación de dos reformas constitucionales -1943 y 1970destinadas a resguardar esta prerrogativa, como se verá más adelante.

Ahora bien, pese a que el Ejecutivo experimentó diversas reformas, conservó gran continuidad respecto del régimen precedente. Por el contrario, la organización del Congreso Nacional fue, seguramente, el capítulo de la Constitución de 1833 que mayores enmiendas sufrió ${ }^{19}$, aunque mantuvo el régimen bicameral, tal como lo ha destacado Bernaschina ${ }^{20}$. Durante la discusión de la Carta de 1925, éste fue un punto particularmente sensible, puesto que Arturo Alessandri era de la opinión de establecer un sistema unicameral, restringiendo ostensiblemente las atribuciones legislativas del Senado, transformándolo en un órgano meramente consultivo, integrado por funcionarios y ex funcionarios públicos, de forma que operase como una Cámara consultiva de carácter técnico-funcional ${ }^{21}$. Pero, después de largos debates, quedaron ambas ramas del Congreso con facultades semejantes en la discusión e iniciativa de las leyes ${ }^{22}$, manteniendo, de esta forma, gran continuidad respecto del régimen de gobierno precedente.

Por su parte, como importante cambio en relación con el Congreso, se consagró constitucionalmente a los partidos políticos, con ocasión del sistema de representación proporcional adoptado para su elección, como veremos a continuación. Sin embargo, nada dijo sobre su relación con el poder Ejecutivo, así como tampoco delimitó un estatuto que contuviese normas mínimas para su funcionamiento. Esta situación fue modificada recién con la reforma constitucional de enero 1971, el "Estatuto de Garantías", que permitió la asunción de Salvador Allende en el cargo de Presidente de la República. Ello por cuanto se les reglamentó con oca-

\footnotetext{
${ }^{16}$ AmunÁtegui, Gabriel, cit. (n. 6), p. 431.

${ }^{17}$ Bernaschina, Mario, cit. (n. 7), p. 299.

${ }^{18}$ Constitución Política de la República de Chile, 18 de septiembre de 1925, artículo 45

${ }^{19}$ Bernaschina, Mario, cit. (n. 7), p. 36.

${ }^{20}$ Ibíd., p. 220.

${ }^{21}$ Ibíd., p. 37.

${ }^{22}$ Ibíd., p. 220.
} inciso 2. 
sión del derecho de asociación al tiempo que se les otorgó personalidad jurídica de derecho público ${ }^{23}$.

De esta manera, en el texto inicial de la Constitución de 1925 se dispuso que "en las elecciones de diputados y senadores se empleará un procedimiento que dé por resultado en la práctica una efectiva proporcionalidad en la representación de las opiniones y de los partidos políticos" ${ }^{24}$. Pese a que se ha sostenido que dicha consagración habría tenido un carácter más bien i n c i d e n $\mathrm{t} \mathrm{a}{ }^{25}$, consideramos que, por el contrario, tuvo un importante papel, por cuanto el citado precepto mantuvo dos lineamientos esenciales en relación al rol de los partidos en el sistema institucional: el de ser actores protagónicos del proceso electoral y el de mantener un vínculo intrínseco con el Congreso Nacional.

En síntesis, desde un punto de vista estático, es posible apreciar cómo el diseño normativo inicial del régimen de gobierno en la Carta de 1925, buscó resolver un problema del pasado, de forma de bloquear aquellas normas que habían permitido al Congreso Nacional jugar un rol protagónico en la forma de gobierno bajo la Constitución de 1833. Pero también, con miras a potenciar el rol del Ejecutivo sobre los demás poderes públicos. Esta visión es concordante con lo observado por Kelsen en 1926, respecto de la Constitución de 1925, Carta que estima relevante analizar atendido a que ella era "producto de aquel movimiento antiparlamentario que hoy se propaga, también en Europa, por doquier”. Tras analizar diversas disposiciones de la Constitución -que estima "impecablemente redactada" - señala que "en la República sudamericana se ha resuelto este problema -la restricción del poder del Parlamento- en forma relativamente moderada, de modo que se ha evitado, en un bien entendido interés de la Nación, salir del régimen parlamentario para caer en el extremo opuesto de una dictadura c a r e n t e de Parlamento" 26 .

Pero, por otro lado, también desde el punto de vista normativo, se mantuvo el carácter bicameral del Congreso - pese a los intentos de Alessandri por modificarlo- al tiempo que se consagró constitucionalmente la existencia de partidos políticos, con ocasión del sistema electoral que iba a regir para la conformación de sus miembros. Como veremos más adelante, y tal como observara Loewenstein con gran lucidez ${ }^{27}$, estos aspectos serán de gran relevancia, ya que se constituirán en factores claves en la relativización de la forma de gobierno presidencialista, desde el punto de vista dinámico.

\footnotetext{
${ }^{23}$ Ley de reforma constitucional $N^{\circ} 17.398,9$ de enero de 1971. Al respecto véase también: Carrasco Delgado, Sergio, Estatuto de Garantías Democráticas, en Revista de Derecho y Ciencias Sociales, 153-154 (1970), p. 124.

${ }^{24}$ Constitución Política de la República de Chile, 18 de septiembre de 1925, artículo 25.

${ }^{25}$ Barros, Enrique, Aspectos jurídicos del estatuto de los partidos políticos, en Estudios Públicos, 14 (1984), p. 173.

${ }^{26}$ Kelsen, Hans, Observaciones sobre la Constitución chilena (traducción de Joaquín García Huidobro de artículo publicado en 1926), en Anuario de Filosofía Jurídica y Social, 20 (2002), pp. 643-646.

${ }^{27}$ Loewenstein, Karl, La presidencia fuera de los Estados Unidos (estudio comparativo de instituciones políticas), en Boletín del Instituto de Derecho Comparado de México, 5 (1949), pp. 23-24.
} 


\section{LA RELATIVIZACIÓN DEL RÉGIMEN PRESIDENCIAL POR EL CONGRESO NACIONAL}

Tras varios años de inestabilidad institucional -República Socialista median$\mathrm{te}^{28}$ - a finales de 1932 entró en vigencia efectiva, finalmente, la Carta de 1925, ya que los poderes públicos Presidente de la República-Congreso Nacional, comenzaron a conformarse en base a sus normas ${ }^{29}$. Al poco andar, fueron apareciendo nuevos mecanismos desde el Congreso que, de forma semejante a los ejercidos bajo la Carta de 1833, comenzaron a relativizar en términos relevantes el diseño normativo del régimen presidencial, aunque sin llegar a generar a una mutación hacia formas de gobierno cercanas al parlamentarismo. Como veremos continuación, éstos no fueron idénticos, ni tampoco implicaron un giro radical en el régimen de gobierno, tal como han sugerido algunos trabajos ${ }^{30}$. Sin embargo, compartieron ciertos rasgos importantes, que permitieron la progresiva relativización del presidencialismo chileno tornándolo más equilibrado.

\section{Un antecedente: la transformación del régimen de gobierno durante la vigencia} de la Carta de 1833

La transformación del régimen de gobierno no es una novedad de la Carta de 1925, sino que tiene su antecedente en la Constitución de 1833. En efecto, ésta contemplaba una autoridad presidencial fuerte, autoritaria que tras décadas se fue progresivamente relativizando, al punto de mutar a formas cercanas o propias del parlamentarismo ${ }^{31}$. Al respecto, Julio Heise plantea que el giro en la forma de gobierno se debió a tres factores: primero, reformas constitucionales acaecidas durante el periodo; segundo, creación de algunas prácticas parlamentarias; y, tercero, interpretación de diversos preceptos constitucionales ${ }^{32}$.

En efecto, las diversas enmiendas aprobadas, a juicio del autor, fueron destruyendo uno a uno "los fundamentos autoritarios del autoritarismo portaliano, dando paso progresivamente a un gobierno de gabinete". Entre las reformas cabe destacar la prohibición de la reelección presidencial inmediata (1871); la consagración de la libertad de reunión, de asociación y de enseñanza (1874); la ampliación de los cargos sujetos a incompatibilidades (1874); el establecimiento de la elección directa y por circunscripción del Senado (1874); la reglamentación

${ }^{28} \mathrm{Al}$ respecto véase: CorreA, Sofía et al., Historia del siglo XX chileno. Balance paradojal (3a ed., Santiago, Editorial Sudamericana, 2005), pp. 107-110. Véase también: PALMA, Eric, El Estado socialista según la legislación irregular de Carlos Dávila (junio-septiembre de 1932), en Estudios Constitucionales, 1 (2017), pp. 373-404.

${ }^{29}$ Carrasco Delgado, Sergio, cit. (n. 9), p. 172.

${ }^{30} \mathrm{Al}$ respecto, véase: Brahm, Enrique; Bertelsen, Raúl; Amunátegui, Andrés, cit. (n. 5); Ibáñez Santa María, Adolfo, cit. (n. 4).

${ }^{31} \mathrm{Al}$ respecto, véase, entre otros: EDWARDS, Alberto, La fronda aristocrática en Chile (17a ed., Santiago, Editorial Universitaria, 2005), pp. 185-196; EyZAGUIRre, Jaime, Historia de las instituciones políticas y sociales (19 a ed., Editorial Universitaria, 2011), pp. 171-177; CAMPOS Harriet, Fernando, cit. (n. 2), pp. 259-263; Bravo Lira, Bernardino, La Constitución de 1833, en Revista Chilena de Derecho, 10 (1983), pp. 325-329; Carrasco Delgado, Sergio, cit. (n. 9), p. 136; Ruiz-Tagle, Pablo, cit. (n.1), p. 110.

${ }^{32}$ Heise, Julio, cit. (n. 2), p. 36. 
y restricción del ámbito de aplicación de las facultades extraordinarias (1874); la incorporación de los senadores y diputados en la composición del Consejo de Estado, órgano consultivo del poder Ejecutivo (1874); la agilización del proceso de reforma constitucional (1882); el reemplazo del veto absoluto por el veto suspensivo (1893); el establecimiento del acuerdo del Senado para los nombramientos diplomáticos (1891); entre otras ${ }^{33}$.

Como puede apreciarse, ninguna de las enmiendas anteriormente descritas estableció instituciones que comúnmente se hallan asociadas a regímenes parlamentarios como interpelaciones, votos de censura o desconfianza, disolución de alguna de las cámaras del Parlamento por parte del Ejecutivo o el establecimiento de la figura del Primer Ministro. Por el contrario, se abocaron a establecer un sistema de frenos y contrapesos al Ejecutivo, reemplazando la división de poderes y funciones, por la confusión de los mismos.

En segundo lugar, el autor destaca la creación de todo un sistema de prácticas parlamentarias destinadas a desarticular el autoritarismo presidencial, conformadas por las interpelaciones y los votos de censura. Las interpelaciones consistieron en la citación de los ministros del gabinete a las Cámaras, para que éstos fuesen interrogados acerca de la marcha del gobierno. Los votos de censura o de desconfianza, por su parte, expresaban una discrepancia entre el gabinete y la mayoría de una de las dos ramas legislativas. Constituían un verdadero recurso de apremio en contra de los ministros del gabinete, a fin que abandonaran sus cargos de manera tal de rectificar el rumbo político del gobierno. Pese a no contar con regulación expresa, terminaron siendo aceptadas como un recurso para hacer efectiva la fiscalización y para estudiar la conducta funcionaria sin llegar a la acusación constitucional o impeachment ${ }^{34}$.

Y, en tercer lugar, Heise destaca la interpretación de preceptos constitucionales en términos parlamentarios. Identifica, por un lado, la norma que disponía la compatibilidad entre las funciones de ministro con las de senador y diputado, la cual habría llevado a que recurrentemente éstos se escogiesen entre los más destacados miembros del Congreso, siendo uno de los rasgos más distintivos del régimen, lo que precisamente le habría dado el carácter parlamentarista. Y, por otro, las leyes periódicas o constitucionales, las cuales fueron el fundamento más efectivo y sólido de la interpretación parlamentarista que se dio a la Carta de $1833^{35}$. Éstas se caracterizaban por el hecho de carecer de un mecanismo de sanción en caso de que no fuesen aprobadas dentro del plazo constitucional por parte del Congreso Nacional. De esta manera, en el evento de no ser despachadas oportunamente, el Presidente quedaba sin una ley que le permitiese, por ejemplo, realizar gasto público o cobrar contribuciones.

En efecto, tal como señala Heise, en materia de presupuesto primaba la voluntad del Congreso, ya que el Ejecutivo no podía ejercer el derecho a veto absoluto, al tiempo que se veía imposibilitado de hacer regir el proyecto que había presentado, puesto que la Constitución no se lo permitía. En ese mismo orden

\footnotetext{
${ }^{33}$ Ibíd., pp. 36-47.

${ }^{34}$ Ibíd., pp. 61-63.

${ }^{35}$ Ibíd., pp. 23-35.
} 
de cosas, contemplaba la autorización de ley, cada 18 meses, para el cobro de las contribuciones, con lo que se otorgaba al Congreso una influencia extraordinaria en el manejo de los negocios del Estado ${ }^{36}$.

En síntesis, como da cuenta Heise, la transformación del régimen de gobierno hacia formas propias del parlamentarismo, se generó producto de la confluencia de tres mecanismos -reformas constitucionales, prácticas parlamentarias e interpretación de preceptos constitucionales- los que, posteriormente, fueron desmantelados con la dictación de la Constitución de 1925, con miras resguardar la posición institucional del Presidente de la República respecto de los demás poderes públicos, particularmente, sobre el Congreso Nacional.

\section{La relativización de la forma de gobierno durante la vigencia de la Constitu-} ción de 1925

Entre finales de 1932, tras el inicio de la segunda administración de Alessandri Palma y 1970, previo a la promulgación de la reforma constitucional promovida durante el gobierno de Frei Montalva, es posible apreciar diversos mecanismos jurídico-políticos que en términos semejantes a los identificados por Heise para la Carta de 1833, fueron determinantes para la relativización del diseño normativo inicial presidencialista de la Constitución de 1925. Si bien, éstos no tuvieron el mismo alcance transformador que en el texto precedente, al punto de generar una "vuelta de tuerca" radical en la práctica de la forma de gobierno, tal como han enunciado algunos autores, destacan por el hecho de haber relativizado en términos relevantes el régimen presidencial, interviniendo en prerrogativas claves del Ejecutivo, posibilitando un mayor equilibrio entre los poderes públicos Presidente de la República-Congreso Nacional. Estos mecanismos, sostenemos, estuvieron conformados por reformas legales, prácticas políticas y legislativas, y la interpretación de preceptos constitucionales.

En efecto, el primer mecanismo lo conformaron las reformas legales que establecieron las denominadas "consejerías parlamentarias". Éstas permitían que tanto el Senado como la Cámara de Diputados pudiesen nombrar dos representantes cada una, en la Junta Central de Beneficencia Pública y en cada consejo de los organismos fiscales, de administración autónoma o semifiscales, de la República.

La Constitución de 1925 establecía un régimen de incompatibilidades cuyo espíritu "era prohibir cualquiera función o comisión retribuida, salvo las de la enseñanza pública" ${ }^{37}$. Sin embargo, el texto original contemplaba dicha incompatibilidad respecto de empleos retribuidos con fondos fiscales o municipales, pero nada decía sobre aquellos provenientes de empresas semifiscales o autónomas. De ahí que se procedió a la dictación de una ley interpretativa de la Constitución -la ley $\mathrm{N}^{\circ} 6.922$ de 1941- que amplió dicha prohibición a los ámbitos señalados. Sin embargo, dicha norma estableció que quedaban exceptuadas "las comisiones $o$ funciones cuya designación corresponda a la Cámara de Diputados y al Senado”. De

\footnotetext{
${ }^{36}$ Ibíd., p. 28.

${ }^{37}$ Bernaschina, Mario, cit. (n. 7), p. 232.
} 
esta manera, teniendo en consideración la excepción anteriormente señalada, se dictó en 1946 la ley $\mathrm{N}^{\circ}$ 8.707, que creaba las consejerías parlamentarias.

Existieron 22 instituciones amparadas por esta ley, donde cada una de ellas contaba con 4 consejeros parlamentarios, vale decir, con un total de 88 congresistas. Ello generó, en la práctica, una relevante fuente de poder político, tanto para los parlamentarios como para los partidos políticos. Para Federico Gil, este poder implicaba una verdadera batalla política en la apertura de cada legislatura ${ }^{38}$. En tal sentido, las consejerías parlamentarias se caracterizaron por el hecho que permitieron al Congreso ir más allá de una mera fiscalización de los actos del Ejecutivo en las empresas del Estado, ya que posibilitaron que los parlamentarios pudiesen tomar parte en el debate del gobierno y administración de dichas empresas.

A juicio de Bernaschina, esta institución no vulneraba la Constitución por cuanto "la ley $\mathrm{N}^{\circ}$ 6.992, al ampliar las incompatibilidades mediante una interpretación constitucional, bien pudo reservar ciertos cargos no sujetos a incompatibilidad, máxime cuando esas comisiones las otorgarán las Cámaras y no el ejecutivo" 39 . Zúñiga, en cambio, sostiene que este nuevo organismo inspirado “en un fortalecimiento de la fi s c a li z a ción parlamentaria”, terminó "vaciando la Constitución en relación a prohibiciones parlamentarias, afectando gravemente el principio de separación de poderes"

De esta manera, una de las principales críticas a las consejerías parlamentarias fue, precisamente, la desviación de la intención inicial que este instituto habría desarrollado en la práctica, pasando de ser un mecanismo de fiscalización de los actos de la administración del Estado, a la participación directa en él. Con ello, se terminaba afectando la separación de poderes y funciones, por cuanto el Congreso terminó inmiscuyéndose en prerrogativas propias del Ejecutivo. De ahí que el partido Demócrata Cristiano, crítico frente a esta situación, promovió su derogación, la que finalmente se concretó en $1961^{41}$.

El segundo mecanismo lo conformaron las prácticas políticas y legislativas, representadas por el pase de partido y por las denominadas leyes $\mathrm{m}$ i s c e lá n e a $s$, respectivamente ${ }^{42}$. El pase de partido era una práctica política que consistía en la autorización que se confería por la directiva de un partido determinado a sus militantes para que éstos pudiesen aceptar una cartera ministerial, intendencia, gobernación o jefatura de un servicio público. Esta práctica solía ir acompañada de la orden de reti ro, instrucción emanada de los partidos políticos, en virtud de la cual éstos intervenían e n la r e m o c ión d e los min is tros, ya que éstos tenían la obligación de dimitir, a riesgo de

${ }^{38}$ GIL, Federico, El sistema político de Chile (Santiago, Editorial Andrés Bello, 1969), p. 126.

${ }^{39}$ Bernaschina, Mario, cit. (n. 7), p. 233.

${ }^{40}$ ZúNiga, Francisco, Constitución y ley interpretativa. Algunas notas sobre una paradoja y peligros relativos a este tipo de ley, en Revista Ius et Praxis, 2 (2009), p. 273.

${ }^{41}$ GIL, Federico, cit. (n. 38), p. 127.

${ }^{42}$ Véase al respecto: Bravo Lira, Bernardino, cit. (n. 4), p. 60; Brahm, Enrique; BerTelsen, Raúl; Amunátegui, Andrés, cit. (n. 5), p. 10; Ibáñez Santa María, Adolfo, cit. (n. 4), pp. 107-110. 
ser expulsados de sus colectividades partidarias ${ }^{43}$. Ésta práctica, a su vez, "tendía a provocar una crisis ministerial, ajena la más de las veces a la voluntad del Presidente de la República" ${ }^{44}$.

Como se señaló anteriormente, una de las motivaciones principales de los constituyentes de 1925 fue suprimir las bases constitucionales del régimen parlamentario precedente. En ese ámbito, se dispuso la expresa incompatibilidad entre los cargos de parlamentario y ministro, de forma de, por un lado, posibilitar una mayor separación de poderes y funciones y, por otra, reforzar la posición institucional del poder presidencial respecto de los demás poderes públicos, particularmente, sobre el Congreso Nacional.

En tal sentido, esta práctica perturbaba la función ejecutiva, toda vez que atentaba contra una de sus prerrogativas exclusivas, ya que se trataba de cargos de su exclusiva confianza. Al respecto, Ibáñez Santa María señala que esta práctica "hizo caducar, en el hecho, la facultad del Presidente de la República para designar a sus colaboradores, por cuanto aquellos nombramientos resultaban de un acuerdo entre el Presidente y los partidos o grupos el que, una vez alcanzado, se concretaba en la designación de alguien de común acuerdo, si es que no se producía una imposición por parte de los partidos, dependiendo de su situación de poder en relación al Presidente de la República” ${ }^{45}$. A juicio del autor, prácticas como el pase de partido, ilustran que la forma de gobierno practicada en el marco de la Carta de 1925 fuese un "parlamentarismo de partidos y grupos" ${ }^{46}$.

Las leyes misceláneas, por su parte, fueron una práctica legislativa de los parlamentarios, que consistía en adicionar en un mismo proyecto de ley, materias de la más diversa índole, perdiendo el proyecto original coherencia respecto de sus ideas matrices y fundamentales. Como se señaló anteriormente, el texto original de 1925 contempló la iniciativa legislativa exclusiva del Ejecutivo en la ley de presupuesto, prerrogativa que tras la reforma de 1943 se amplió a otros ámbitos. Asimismo, se limitó el actuar del Congreso sobre ellas al permitirle solamente aprobar, rechazar o disminuir, quedando vetado, por tanto, aumentar o crear los servicios, empleos, emolumentos o aumentos que se propongan.

Sin perjuicio de lo anterior, a mediados de la década del 50, señala Tapia Valdés, se aprecia un mayor grado de intensidad de esta práctica. En efecto, ilustra el autor, "todo proyecto cuya dictación reclamaba urgentemente la ciudadanía o el Ejecutivo, por referirse a mejoramientos económicos o nuevos impuestos, era aprovechado por los parlamentarios, en un segundo trámite en la Cámara revisora, para obtener la aprobación de las medidas más diversas, con el objeto de satisfacer las exigencias de las organizaciones gremiales del capital o del trabajo,

\footnotetext{
${ }^{43}$ Bernaschina, Mario, cit. (n. 7), pp. 365-366.

${ }^{44}$ Carrasco Delgado, Sergio, Algunas consideraciones históricas relativas a un ordenamiento constitucional, en Revista Chilena de Derecho, 6 (1979), p. 142. Véase también: CARRASCO DELGADO, Sergio, Estabilidad e importancia política de los ministros de Estado. El caso del ministro de Hacienda (1925-1973), en: Revista de Derecho Público, 59 (1996), p. 142.

${ }^{45}$ Ibáñez SAnta María, Adolfo, cit. (n. 4), p. 109.

${ }^{46}$ Ibíd., p. 110.
} 
de instituciones regionales y aun de los simples particulares" ${ }^{\prime 7}$. De esta manera, "los parlamentarios, frente a la postergación de sus proyectos", producto de la constante invocación por parte del Ejecutivo del mecanismo de urgencias, "sólo les quedaba incorporarlos, por la vía de la indicación” ${ }^{48}$. Por tanto, a través de esta práctica legislativa se doblegaban prerrogativas como la iniciativa legislativa del Presidente de República y el régimen de las urgencias. El Ejecutivo se veía obligado a aceptarlas, si es que quería obtener la aprobación oportuna de su proyecto por parte del Congreso.

Finalmente, el tercer mecanismo de morigeración de la forma de gobierno lo conformó la interpretación de preceptos constitucionales, particularmente, la norma que regulaba las le yes de gracia. En efecto, con ocasión de la regulación de las materias de ley, se establecía dentro de sus hipótesis d a r p e ns i o n e s. Respecto de ellas, se establecía que para ser aprobadas se requerían de los dos tercios de los miembros presentes en cada Cámara ${ }^{49}$. Se trataba de la única materia de ley con quórum supramayoritario de la Constitución de 1925, lo que da cuenta de la intensión del constituyente de conferir un carácter excepcional a esta institución.

Las leyes de gracia, que en su diseño normativo inicial tenían un carácter restringido, al poco andar fueron reinterpretadas en favor del Congreso Nacional, órgano que había visto mermado en términos relevantes sus prerrogativas en materia de gasto público. En efecto, entre el advenimiento del Frente Popular en 1938 y el término del segundo gobierno de Carlos Ibáńez en 1958, éstas representaron, según cifras de Tapia Valdés, el 55\% de las leyes despachadas durante dicho periodo. Silva Bascuñán, de igual forma, señala que entre 1957 y 1961, de 2.109 leyes promulgadas, el $68 \%$ se abocó a este tipo de materias ${ }^{50}$. Valenzuela y Wilde, por su parte, señalan que esta proporción varió considerablemente entre 1958 y 1968, elevándose a más de un 70\% en 1964 y 1965, para declinar drásticamente, en los años intermedios del gobierno de Frei Montalva, a 35\% y 17\%, y para elevarse una vez más a 52\% a medida que se aproximaban las elecciones de $1970^{51}$.

Estas cifras ilustran, en opinión de Tapia Valdés, cómo "se ha desvirtuado totalmente su significación originaria, de premiar a quienes hubieren comprometido la gratitud nacional". En efecto, sostiene que a través de ellas se "dispensan favores simplemente a quienes conmueven, con verdades o mentiras, al espíritu compasivo de los congresistas". O bien, "con los abonos de tiempo se favorece a los amigos que quieren mejorar su jubilación" 52 .

Como queda en evidencia, este tipo de normas, pese a tener un quórum su-

${ }^{47}$ Tapia Valdés, Jorge, La técnica legislativa (Santiago, Editorial Jurídica de Chile, 1960), p. 43.

${ }^{48}$ ANDRADE, Carlos, Elementos de derecho constitucional chileno (2a ed., Santiago, Editorial Jurídica de Chile, 1971), p. 436.

${ }^{49}$ Constitución Política de la República de Chile, 18 de septiembre de 1925, artículo 44 № 5.

${ }^{50}$ Silva Bascuñán, Alejandro, Tratado de derecho constitucional, Tomo III: La Constitución de 1925 (Santiago, Editorial Jurídica de Chile, 1963), II, p. 148.

${ }^{51}$ Valenzuela, Arturo y WiLde, Alexander, El Congreso y la redemocratización en Chile, en Alternativas, 3 (1984), p. 21.

${ }^{52}$ Tapia Valdés, Jorge, cit. (n. 44), p. 47. 
pramayoritario, representaron por varias décadas más del 50\% de la legislación despachada por el Congreso Nacional. Ello, a todas luces, da cuenta de la reinterpretación de este instituto, en un sentido amplio, permitiendo la actuación de los parlamentarios en materia de gasto público, ámbito restringido tanto en la versión original de la Constitución de 1925 como en la reforma constitucional de 1943.

En síntesis, es posible apreciar cómo, en términos semejantes a lo postulado por Julio Heise para la Carta de 1833, durante la vigencia de la Constitución de 1925 reformas legales, prácticas políticas y legislativas, y la interpretación de preceptos constitucionales fueron relativizando con éxito el control de la administración del Estado (consejerías parlamentarias), el manejo del gasto público (leyes de gracia), la elección y remoción de funcionarios de exclusiva confianza del Ejecutivo (pase y orden de partido), así como la iniciativa exclusiva y el régimen de urgencias (leyes misceláneas). Con estos mecanismos, el poder del Presidente de la República, desde el punto de vista del diseño normativo, se vio fuertemente relativizado, dando cuenta de un régimen presidencial más equilibrado, con fuertes contrapesos institucionales provenientes del Congreso Nacional.

Al respecto, resulta ilustrativo lo observado por Loewenstein a mediados de la década de 1940 sobre la Constitución de 1925, Carta que considera "uno de los mejores instrumentos hispanoamericanos que logró conservar los procedimientos constitucionales, aún en estos tiempos agitados". En efecto, y a diferencia de Kelsen, señala sobre la forma de gobierno en Chile que "el Congreso está en posición de contrarrestar la supremacía presidencial”. Ello por cuanto "el gabinete, que con el Presidente comparte el Poder Ejecutivo, no puede gobernar sin el consentimiento parlamentario. Aun cuando se mantenga la poderosa dirección del Presidente, ésta se halla atenuada por el contrapeso parlamentario" ${ }^{53}$.

\section{El REFORZAMIENTO DEL RÉGIMEN PRESIDENCIALISTA VÍA REFORMA}

\section{CONSTITUCIONAL}

Los mecanismos jurídico-políticos anteriormente señalados, posibilitaron la relativización del diseño inicial del régimen de gobierno promovido por la Constitución de 1925. Sin perjuicio de aquello, tras diez años de su vigencia efectiva, es posible apreciar el primero de cuatro intentos por desarticularlos, de forma de lograr afianzar, en la práctica, el poder presidencial.

En efecto, la opción por un presidencialismo reforzado tuvo sus primeros antecedentes con la reforma de 1943. En ella se ampliaron las materias de iniciativa legislativa exclusiva del Ejecutivo -antaño limitadas a la ley de presupuesto- a la división política o administrativa del país; la creación de nuevos servicios públicos o empleos rentados; y la concesión o aumento de sueldos y gratificaciones al personal de la administración pública de las empresas fiscales y de las instituciones semifiscales. Respecto de dichas materias, se introdujo una importante limitación al Congreso Nacional, por cuanto de dispuso que éste sólo podría aceptar, disminuir o rechazar los servicios, empleos, emolumentos o aumentos que el Presidente

${ }^{53}$ Loewenstein, Karl, cit. (n. 27), pp. 23-24. 
de la República propusiera. Por tanto, quedaba vetada la facultad de aumentar o crear, como se señaló anteriormente. Sin embargo, como destaca Faúndez, pese a estas limitaciones, no le impedía a los parlamentarios "enviar proyectos de ley que llamaran a aumentar los pagos en el sector privado" 54 .

Asimismo, se entregó la potestad al Presidente de la República de firmar decretos de emergencia económica, a través de los cuales se le autorizaba para decretar pagos no autorizados por ley, en caso de calamidades públicas, de agresión exterior, de conmoción interna o del agotamiento de los recursos destinados a mantener servicios que no puedan paralizarse sin grave daño para el país. Se dispuso como límite que éstos no podía exceder el dos por ciento del monto autorizado por la ley de presupuesto de aquel año ${ }^{55}$.

Posteriormente, en 1955, durante el gobierno de Carlos Ibáñez del Campo, se nombró una comisión encargada de "restaurar el espíritu y la letra de la Constitución de 1925, o sea, reafirmar el régimen presidencial de gobierno”. Sin embargo, el trabajo realizado no logró traducirse en un proyecto de reforma constitucional $^{56}$. Por su parte, en 1964, el presidente Jorge Alessandri Rodríguez envió un proyecto de reforma constitucional al Congreso Nacional, destinado a potenciar el rol del Presidente de la República en el entramado institucional, centralizando el manejo económico y financiero en el Ejecutivo ${ }^{57}$, con miras a llevar adelante un proyecto de modernización capitalista promovido durante los primeros años de su presidencia ${ }^{58}$. Pese a que esta reforma no llegó a concretarse, da cuenta de un enfoque decididamente tecnocrático de gestión, articulado desde el Ejecutivo, que sería reafirmado en el periodo siguiente.

$\mathrm{Al}$ igual que sus antecesores, Eduardo Frei Montalva apostó por implementar una política de planificación tecnocrática y centralizada, conducida por el Ejecutivo, política que dio inicio a lo que Mario Góngora denomina “época de planificaciones globales”, denominado en el caso del gobierno demócrata cristiano "revolución e n libertad" 59 . Sin embargo, a diferencia de los tres intentos anteriormente señalados, tuvo gran éxito, ya que la dictación de la reforma constitucional de 1970 no solo bloqueó aquellos mecanismos que habían permitido relativizar el diseño original del régimen de gobierno establecido en la Carta de 1925, sino que, al mismo tiempo, afianzó aún más la posición institucional del Presidente de la República en claro desmedro del Congreso Nacional.

Al respecto, Cumplido señala que bajo la Carta de 1925 "el legislador ha descendido a detalles propios de la potestad reglamentaria del Presidente de la República", por lo que "la mayoría de las leyes de esta época pueden aplicarse sin

\footnotetext{
${ }^{54}$ FAúndeZ, Julio, cit. (n. 4), p. 129.

${ }^{55}$ Ley de reforma constitucional $\mathrm{N}^{\circ} 7.727,23$ de noviembre de 1943.

${ }^{56}$ Carrasco delgado, Sergio, cit. (n. 9), p. 189.

${ }^{57}$ Carrasco delgado, Sergio, Alessandri: su pensamiento constitucional. Reseña de su vida pública (Santiago, Editorial Jurídica de Chile, 1987), pp. 81-97.

${ }^{58}$ Correa, Sofía, Con las riendas del poder. La derecha chilena en el siglo XX (Santiago, Editorial Sudamericana, 2004), pp. 223-228.

${ }^{59}$ GÓNGORA, Mario, Ensayo histórico sobre la noción de Estado en Chile en los siglos XIX y XX (9a ed., Santiago, Editorial Universitaria, 2006) pp. 280-288.
} 
reglamento". A su juicio, "parece que el Congreso Nacional ha cobrado revancha del fortalecimiento de las atribuciones del Ejecutivo consagradas en la Constitución de 1925 y reforzadas en las modificaciones constitucionales posteriores" ${ }^{60}$. De esta forma, como veremos a continuación, la reforma de 1970, por una parte, suprimió aquellos mecanismos que hasta ese entonces habían equilibrado el régimen de gobierno presidencialista. Y, por otra, reforzó las potestades presidenciales, en claro desmedro del Congreso Nacional.

\section{El término de los mecanismos juridico-políticos de morigeración del régimen de gobierno}

La reforma constitucional de 1970 bloqueó con éxito los mecanismos que hasta esa fecha habían posibilitado la relativización del diseño normativo inicial de la forma de gobierno previsto en la Constitución de 1925. Al respecto, Frei Montalva, justificando los lineamientos centrales de esta reforma, señalaba que la Carta de 1925, si bien había logrado eliminar el régimen parlamentario precedente, de todas formas "siguieron subsistiendo zonas oscuras en el ámbito constitucional que permitieron nuevamente al Parlamento interferir en la vida administrativa del país y limitar, en el hecho, las prerrogativas que las Constituciones del 33 y del 25 le habían dado al Presidente de la República como Jefe Supremo de la Nación y administrador del Estado" ${ }^{61}$. Así, frente a la práctica legislativa de las leyes misceláneas se introdujo el concepto de "ideas matrices o fundamentales del proyecto". Al respecto, Frei Montalva manifestaba una posición bastante crítica de esta práctica, ya que consideraba que éstas se habían prestado "para el abuso frecuente de que se aproveche una ley importante para introducirles disposiciones destinadas a favorecer a determinados grupos y aun a personas individuales y que significa hacer de las leyes una maraña ininteligible para el hombre común y aún difícil de entender por los intérpretes avezados" ${ }^{2}$.

De esta manera, la introducción de esta reforma "fue más allá del estado de cosas existentes, exigiendo una conexión entre las ideas matrices y toda modificación, corrección y adición que se introduzca a los proyectos”. Ello por cuanto se buscaba "extender la limitación no solo a las indicaciones introducidas por los parlamentarios, sino también por el Ejecutivo" ${ }^{63}$. A juicio de Soto Velasco, con esta enmienda "disminuyeron los incentivos existentes hasta ese momento para que los parlamentarios comprometieran su voto en proyectos relevantes a cambio de una norma que permitiera, por ejemplo, dar por cumplido un compromiso electoral o beneficiar a un grupo de interés" ${ }^{64}$.

${ }^{60}$ Cumplido, Francisco, La especificación de la ley, en Frei Montalva, Eduardo et al., Reforma constitucional de 1970 (Santiago, Editorial Jurídica de Chile, 1970), p. 180.

${ }^{61}$ Frei Montalva, Eduardo et al., Reforma, cit. (n. 60), p. 19.

${ }^{62}$ Ibíd., p. 47.

${ }^{63}$ Fermandois, Arturo y GarCía, José Francisco, Origen del presidencialismo chileno: reforma constitucional de 1970, ideas matrices e iniciativa legislativa exclusiva, en Revista chilena de Derecho, 36 (2009), p. 288.

${ }^{64}$ Soto Velasco, Sebastián, Congreso Nacional y proceso legislativo. Teoría y práctica (Santiago, Thomson Reuters, 2015), p. 309. 
En cuanto a la interpretación de preceptos constitucionales, específicamente, las leyes de gracia, que tuvieron un primer intento de modificación en $1943^{65}$, la reforma de 1970 dejó su formulación dentro de las materias que quedaban bajo la iniciativa exclusiva del Presidente de la República ${ }^{66}$. Con ello, se sustraía la única prerrogativa que le había permitido al Congreso Nacional, en términos expresos, crear o aumentar gasto público.

Con todo, cabe hacer presente que, si bien la reforma constitucional de 1970 tuvo un rol determinante en la supresión de los mecanismos jurídico-políticos, durante la segunda mitad del siglo XX, algunos de éstos comenzaron paulatinamente a ser eliminados o caer en franca ineficacia. Tal es el caso de las consejerías parlamentarias, las cuales fueron derogadas en 1961. Por su parte, la práctica política del pase de partido, presente desde la segunda presidencia de Alessandri Palma, persistió hasta mediados de la década de $1960^{67}$, cayendo en desuso tras la asunción de Frei Montalva, quien gobernó prescindiendo de alianzas partidarias, a diferencia de los gobiernos precedentes ${ }^{68}$.

\section{El establecimiento de un régimen presidencial reforzado}

La reforma de 1970 no se limitó a bloquear normativamente las prácticas, leyes e interpretaciones que habían posibilitado equilibrar el régimen presidencial. Al mismo tiempo, incorporó otras enmiendas destinadas a reforzar la posición institucional del Presidente de la República sobre los demás poderes públicos.

En efecto, la reforma de 1970, siguiendo la tendencia iniciada en la Carta de 1925 en su versión original y continuada con la enmienda de 1943, amplió las materias de iniciativa exclusiva del Presidente de la República a tributos, salarios del sector privado, regímenes de seguridad social, pensiones de gracia y otros beneficios económicos. Para Frei Montalva, con esta reforma, se "dotó al Presidente de la República, por primera vez en la historia constitucional de Chile, de las facultades necesarias para llevar adelante una política de planificación económica y social sin interferencias del Parlamento" ${ }^{69}$.

Asimismo, se amplió el mecanismo de urgencias, de manera que se mantuvo el plazo de 30 días para el primer o segundo trámite constitucional, pero lo redujo a 15 días en caso de uno posterior, elevando a rango constitucional la norma contenida en el reglamento interno del Senado ${ }^{70}$. Sin embargo, como bien hace ver Cumplido, "no se estableció ninguna sanción jurídica para el caso en que la respectiva Cámara no despache el proyecto con urgencia, dentro del plazo constitucional", pese a que ello se había previsto en el proyecto original enviado por

\footnotetext{
${ }^{65}$ Bernaschina, Mario, cit. (n. 7), pp. 399-400.

${ }^{66}$ Valencia Avaria, Luis, cit. (n. 13), p. 249.

${ }^{67}$ IbáNez Santa María, Adolfo, cit. (n. 4), p. 110.

${ }^{68}$ SCUlLy, Timothy, Los partidos de centro y la evolución política chilena (Santiago, CiePLAN - Notre Dame, 1992), p. 204.

${ }^{69}$ Frei Montalva, Eduardo et al., cit. (n. 60), p. 40.

${ }^{70}$ Andrade, Carlos, cit. (n. 48), p. 436.
} 
el Ejecutivo al Parlamento. De esta manera, sólo queda "la posible sanción moral y política en el caso de incumplimiento"71.

De igual forma, introdujo una importante modificación en materia de comisiones mixtas, institución instaurada en la versión inicial de la Carta de 1925, consistente en entregar la autorización constitucional para que, en el reglamento interno de cada una de las Cámaras, se regulara la supresión de un trámite constitucional, reemplazándolo por esta instancia. Con todo, la reforma en cuestión dispuso que no podría "omitirse la discusión y votación particular en la Sala de los proyectos de reforma constitucional; los que reglamenten, restrinjan o suspendan los derechos constitucionales o sus garantías; los relativos a la nacionalidad, ciudadanía o elecciones; los que establezcan, modifiquen o supriman contribuciones; los que autoricen la declaración de guerra; los que se refieran a delegación de facultades legislativas y los que versen sobre tratados internacionales"72. Se trata de una reforma que, en opinión de Frei Montalva, busca racionalizar el Poder Legislativo, enfocado a proyectos de ley de mucha complejidad o importancia. De esta manera, "dichos reglamentos podrán establecer normas en virtud de las cuales, una vez aprobado en general un proyecto de ley por la respectiva Cámara, queda su discusión y votación particular entregada a la correspondiente Comisión dentro de las reglas que se señalan"73.

Otra reforma relevante fue la consagración constitucional de la delegación de facultades legislativas para la dictación de decretos con fuerza de ley, práctica venida del régimen parlamentario, seguida con la dictación de la Carta de $1925^{74}$, pero haciéndola coincidente con las materias que quedaban a iniciativa exclusiva del Presidente de la República 75 . Como señala Evans, la "Legislación Delegada se había transformado, con el curso de los años, en una costumbre constitucional, fuera, es cierto de la letra de la Carta de 1925, pero impuesta por los hechos y situaciones de la vida nacional"76. En efecto, entre 1925 y 1969 se dictaron 25 leyes que delegaban facultades legislativas. A juicio de Cordero, el propósito de esta reforma fue "evitar que por la vía de las delegaciones se pudiera regular los derechos que la Constitución asegura a las personas, de manera que su ámbito natural queda reducido a los aspectos internos del aparato estatal"77.

Por su parte, modificó la prerrogativa presidencial de convocatoria a plebiscito, la cual estaba inicialmente establecida -en el contexto del trámite de reforma constitucional- para el caso que el Presidente de la República no hubiese estado de acuerdo con el voto de insistencia del Congreso, tras haber invocado la prerro-

${ }^{71}$ Cumplido, Francisco, La especificación de la ley, en Frei Montalva, Eduardo et al., cit. (n. 60), p. 175.

${ }^{72}$ Ley de reforma constitucional $\mathrm{N}^{\circ} 17.284,23$ de enero de 1970.

${ }^{73}$ Frei Montalva, Eduardo et al., cit. (n. 60), p. 48.

${ }^{74}$ Bronfman, Alan, Génesis de la delegación legislativa en el régimen constitucional de 1925 , en Revista de Estudios Histórico-Jurídicos, 40 (2018), pp. 309-340.

${ }^{75}$ Fermandois, Arturo y García, José Francisco, cit. (n. 59), p. 297.

${ }^{76}$ Evans, Enrique, La delegación de facultades legislativas, en Frei Montalva, Eduardo et al., cit. (n. 60), p. 113.

${ }^{77}$ Cordero, Eduardo, La legislación delegada en el derecho chileno y su función constitucional, en Estudios Constitucionales, 2 (2010), p. 60. 
gativa de veto. Con esta reforma, se dispuso que ésta pudiera ejercerse, además, cuando éste se viese enfrentado al rechazo del Congreso, en cualquier estado de tramitación de un proyecto de reforma constitucional. Asimismo, cuando hubiesen sido rechazadas las indicaciones incorporadas por el Presidente al proyecto de reforma constitucional, vía veto aditivo, tras la aprobación del Congreso Pleno. Como destaca Bronfman, "la norma permitía, en teoría, cubrir una mayor gama de desacuerdos entre Presidente y Congreso, limitando la facultad del Poder Ejecutivo de rechazar de manera total un proyecto de reforma constitucional aprobado por el Congreso Pleno"78. Frei Montalva considera que esta enmienda "constituye la más trascendental de las reformas aprobadas por el Congreso, ya que abre dentro de la ley el camino para las futuras reformas de las instituciones fundamentales del país sin quebrar la tradición jurídica que ha caracterizado la historia política de Chile”. De esta forma, agrega, "el país tendrá los instrumentos para afrontar los problemas más esenciales que se le presentarán inevitablemente a Chile, como a todas las sociedades contemporáneas, en especial a los países que tienen que vencer un grado inferior de desarrollo para lograr su plena expresión humana"79.

Finalmente, se instauró un Tribunal Constitucional cuya inspiración principal habría sido, según Frei Montalva, "resolver los conflictos de carácter jurídico que surjan entre el Ejecutivo y el Congreso, a propósito de la dictación de leyes, cuando existan dudas respecto a la constitucionalidad de preceptos contenidos en los proyectos de leyes que se encuentran en tramitación parlamentaria" Sin embargo, atendido el giro presidencialista de la reforma, en realidad ésta habría tenido un objeto más preciso: establecer un órgano destinado a controlar que tanto las nuevas prerrogativas entregadas al Ejecutivo como las limitaciones establecidas al Congreso Nacional, fuesen respetadas por los parlamentarios. En efecto, se dispuso que este nuevo Tribunal Constitucional le correspondiera, entre otras atribuciones, "resolver las cuestiones sobre constitucionalidad que se susciten durante la tramitación de los proyectos de ley y de los tratados sometidos a la aprobación del Congreso" $"$.

Reflejo de ello, es que se optó por un modelo constitucional excepcionalísimo en la tradición europeo-continental, conformado por el Consejo Constitucional francés, caracterizado por ejercer un control preventivo, que para la época era considerado -por autores como Cappelletti-, como un órgano político no jurídico. En efecto, el autor sostiene de forma tajante que "es bastante clara $-y$ en mayor o menor grado reconocida abiertamente por el resto de los tratadistas franceses- la naturaleza no propiamente jurisdiccional de la función ejercida por el Conseil Constitutionnel, y ello no solamente, como escribe un autor, debido a la naturaleza más bien política que judicial del órgano, que se revela tanto en la selección de sus miembros que la conforman, sino especialmente, en sus diversas

\footnotetext{
${ }^{78}$ Bronfman, Alan, Mecanismos de democracia directa en Chile: los plebiscitos y consultas comunales, en Revista de Derecho, 28 (2007), p. 243.

${ }^{79}$ Frei Montalva, Eduardo et al., cit. (n. 60), p. 46.

${ }^{80}$ Ibíd., p. 48.

${ }^{81}$ Ley de reforma constitucional $\mathrm{N}^{\circ} 17.284,23$ de enero de 1970.
} 
atribuciones y en su forma de operar; pero también y particularmente, por el carácter preventivo de la función de control ejercida por dicho organismo" ${ }^{2}$.

En tal sentido Silva Cimma, primer presidente de este órgano, sostiene que "más que jurídicas las ideas que condujeron a la creación del Tribunal Constitucional fueron predominantemente políticas, asignándole un importante rol como instrumento para el predominio de la política presidencialista". Por tal motivo, a su juicio, "no es de extrañarse que los fallos del Tribunal, en su mayoría, dieran la razón al Ejecutivo". En efecto, agrega que "es fácilmente demostrable que la gran parte de las reclamaciones presentadas eran la consecuencia de actos en que el Congreso pretendía alzaprimar su criterio por sobre el del Jefe de Estado" ${ }^{83}$.

En síntesis, la reforma de 1970 tuvo una doble importancia en el futuro del régimen de gobierno. Por un lado, suprimió normativamente aquellos mecanismos ejercidos por el Congreso Nacional, que habían permitido relativizar con éxito su diseño normativo inicial. Y, por otra, fortaleció en términos relevantes las prerrogativas del Ejecutivo en claro desmedro de los demás poderes públicos, especialmente respecto del Congreso. De esta forma, con esta enmienda se puso término a la relativización que hasta ese entonces había permitido equilibrar el régimen presidencialista diseñado por la Carta de 1925.

Bajo este escenario, el giro presidencialista quedaba afianzado tanto en términos prácticos como normativos, lo que tornó mucho más relevante y decisivo la obtención de sillón presidencial. Sin embargo, rápidamente, el nuevo esquema modelado a partir de las recién inauguradas reformas constitucionales, mostró la debilidad que había provocado en el sistema institucional, ya que debió mediar la suscripción de un "Estatuto de Garantías Democráticas" ${ }^{44}$, enmienda que posibilitó que el Congreso Pleno ratificara la elección del candidato de la Unidad Popular, Salvador Allende, como Presidente de la República ${ }^{85}$. El gobierno de la Unidad Popular, al igual que su antecesor, practicó el nuevo enfoque del régimen de gobierno, esta vez, para implementar "el socialismo a la chilena" ${ }^{\text {. }}$.

Con todo, hay que considerar que a esas alturas habían sido desarticulados exitosamente los mecanismos que permitieron al Congreso Nacional relativizar el régimen de gobierno. Si bien Salvador Allende, semanas previas al Golpe de Estado del 11 de septiembre de 1973, intentó un acercamiento por medio de la reanudación de las conversaciones con la Democracia Cristiana, con Patricio Aylwin como presidente del partido, a instancias del cardenal Raúl Silva Henríquez, estas se vieron frustradas, dado el clima de polarización reinante ${ }^{87}$. Para ese

${ }^{82}$ Cappelletti, Mauro, El control judicial de la constitucionalidad de las leyes en el derecho comparado (México D.F., UnAm, 1966), pp. 11-12.

${ }^{83}$ Silva Cimma, Enrique, El Tribunal Constitucional de Chile (2a ed., Santiago, Cuadernos del Tribunal Constitucional, 2008), pp. 24-25. Véase también: Meléndez, Felipe, La influencia del control preventivo en el diseño normativo del régimen presidencial chileno, en Anuario Iberoamericano de Justicia Constitucional, 21 (2017), pp. 84-89.

${ }^{84}$ Ley de reforma constitucional $\mathrm{N}^{\circ} 17.398,9$ de enero de 1971.

${ }^{85}$ Correa, Sofía et al., cit. (n. 25), p. 264.

${ }^{86}$ GÓNGOra, Mario, cit. (n. 55), p. 280.

${ }^{87}$ Correa, Sofía et al., cit. (n. 25), p. 272. 
entonces, el Congreso había sido despojado de los mecanismos institucionales que le posibilitaron en el pasado relativizar con éxito el poder presidencial.

\section{Conclusiones}

Desde finales de 1932 hasta septiembre de 1973, la forma de gobierno practicada bajo la Constitución de 1925 no fue única ni uniforme. Por el contrario, el régimen presidencialista tuvo relevantes variaciones, siendo posible identificar tres momentos y tipologías. En primer lugar, un presidencialismo fuerte, reflejado en el diseño normativo inicial del texto constitucional, previo a su entrada en vigencia efectiva. En segundo lugar, un presidencialismo equilibrado, presente desde mediados de la década del 30 hasta finales de la década del 60. Y, en tercer lugar, un presidencialismo reforzado, a través de la reforma constitucional de 1970.

Las variaciones del régimen presidencialista se generaron, principalmente, producto del uso de diversos mecanismos jurídico-políticos -semejantes a los utilizados bajo la Carta de 1833- por parte del Congreso Nacional, destinados a contrarrestar las fuertes prerrogativas que la Constitución de 1925 le otorgaba al Ejecutivo. Éstos estuvieron conformados por reformas legales, prácticas políticas y legislativas, y por la interpretación de preceptos constitucionales, los cuales terminaron equilibrando con éxito el presidencialismo fuerte establecido en el texto constitucional. Estos mecanismos si bien fueron de suma relevancia, no tuvieron el mismo impacto que los practicados durante la vigencia de la Carta de 1833, al punto de generar, tal como han sugerido algunos autores, un retorno al parlamentarismo. Ello por cuanto las reformas legales, las prácticas políticas y legislativas, y la interpretación de preceptos constitucionales, más que desplazar al Ejecutivo en la conducción del gobierno, propiciaron la participación e intervención del Congreso Nacional en prerrogativas propias de éste. De ahí que tanto el texto original de 1925 como la reforma de 1943 no fueran suficientes en el cometido de delimitar el ámbito de influencia del Congreso Nacional en el régimen presidencial. La situación cambió con la reforma constitucional de 1970, la cual, por una parte, bloqueó normativamente estos mecanismos y, por otra, reforzó la posición institucional del Ejecutivo sobre los demás poderes públicos. Este nuevo escenario mostró rápidamente su debilidad, atendido a que debió mediar inmediatamente otra reforma constitucional -el Estatuto de Garantías Democráticas- a fin de delimitar las grandes prerrogativas con que asumiría la presidencia Salvador Allende, esta vez, para impulsar otra planificación global, el "socialismo a la chilena", proyecto que terminó abruptamente con el quiebre institucional del 11 de septiembre de 1973. 


\section{Bibliografía CITADA}

Amunátegui, Gabriel, Manual de derecho constitucional (Santiago, Editorial Jurídica de Chile, 1950).

Andrade, Carlos, Elementos de derecho constitucional chileno (2a ed., Santiago, Editorial Jurídica de Chile, 1971).

BARROS, Enrique, Aspectos jurídicos del estatuto de los partidos politicos, en Estudios Públicos, 14 (1984), pp. 171-217.

Bernaschina, Mario, Manual de derecho constitucional (2a ed., Santiago, Editorial Jurídica de Chile, 1955).

Brahm, Enrique, ¿Volver a la Constitución de 1925? Una propuesta sin fundamento histórico, en Revista Chilena de Derecho, 46 (2019), pp. 79-97.

Brahm, Enrique; Bertelsen, Raúl; Amunátegui, Andrés, Régimen de gobierno en Chile: ¿presidencialismo o parlamentarismo? 1925-1973 (Santiago, Editorial Jurídica de Chile, 2002).

Bravo Lira, Bernardino, Régimen de gobierno y partidos politicos en Chile 1924-1973 (Santiago, Editorial Jurídica de Chile, 1978).

- La Constitución de 1833, en Revista Chilena de Derecho, 10 (1983), pp. 317-329.

Bronfman, Alan, Mecanismos de democracia directa en Chile: los plebiscitos y consultas comunales, en Revista de Derecho, 28 (2007), pp. 237-265.

-Génesis de la delegación legislativa en el régimen constitucional de 1925, en Revista de Estudios Histórico-Jurídicos, 40 (2018), pp. 309-340.

Campos Harriet, Fernando, Historia constitucional de Chile. Las instituciones sociales y políticas (4a ed., Santiago, Editorial Jurídica de Chile, 1969).

CAPPELletTI, Mauro, El control judicial de la constitucionalidad de las leyes en el derecho comparado (México D.F., Unam, 1966).

Carpizo, Jorge, Concepto de democracia y sistema de gobierno en América Latina (2a reimp., México D.F., Unam, 2009).

Carrasco Delgado, Sergio, Estatuto de garantías democráticas, en Revista de Derecho y Ciencias Sociales, 153-154 (1970), p. 121-128.

- Algunas consideraciones históricas relativas a un ordenamiento constitucional, en Revista Chilena de Derecho, 6 (1979), pp. 137-148.

- Alessandri: su pensamiento constitucional. Reseña de su vida pública (Santiago, Editorial Jurídica de Chile, 1987).

- Estabilidad e importancia política de los ministros de Estado. El caso del ministro de Hacienda (1925-1973), en Revista de Derecho Público, 59 (1996), pp. 131-150.

-Génesis y vigencia de los textos constitucionales chilenos (3a ed., Santiago, Editorial Jurídica de Chile, 2002).

Cea Egaña, José Luis, Derecho constitucional chileno (3a ed., Santiago, Ediciones UC, 2015), I.

Cordero, Eduardo, La legislación delegada en el derecho chileno y su función constitucional, en Estudios Constitucionales, 2 (2010), pp. 49-86.

Correa, Sofía et al., Historia del siglo XX chileno. Balance paradojal ( $3^{a}$ ed., Santiago, Editorial Sudamericana, 2005.

Correa, Sofía, Con las riendas del poder. La derecha chilena en el siglo XX (Santiago, Editorial Sudamericana, 2004).

-Los procesos constituyentes en la Historia de Chile. Lecciones para el presente, en Estudios Públicos, 137 (2015), pp. 43-85. 
Cumplido, Francisco, La especificación de la ley, en Frei Montalva, Eduardo et al., Reforma constitucional de 1970 (Santiago, Editorial Jurídica de Chile, 1970), pp. 179-195.

EDWARDS, Alberto, La fronda aristocrática en Chile (17 a ed., Santiago, Editorial Universitaria, 2005).

Evans, Enrique, La delegación de facultades legislativas, en Frei MONTALVA, Eduardo et al., Reforma constitucional de 1970 (Santiago, Editorial Jurídica de Chile, 1970), pp.109-154.

Eyzaguirre, Jaime, Historia de las instituciones politicas y sociales de Chile (19a ed., Santiago, Editorial Universitaria, 2011).

Faúndez, Julio, Democratización, desarrollo y legalidad. Chile, 1831-1973 (Santiago, Ediciones Universidad Diego Portales, 2011).

Fermandois, Arturo y García, José Francisco, Origen del presidencialismo chileno: reforma constitucional de 1970, ideas matrices e iniciativa legislativa exclusiva, en Revista Chilena de Derecho, 36 (2009), pp. 281-311.

Frei Montalva, Eduardo et al., Reforma constitucional de 1970 (Santiago, Editorial Jurídica de Chile, 1970).

GIL, Federico, El sistema político de Chile (Santiago, Editorial Andrés Bello, 1969).

GÓngora, Mario, Ensayo histórico sobre la noción de Estado en Chile en los siglos XIXY $X X$ (9a edición, Santiago, Editorial Universitaria, 2006).

HeISE, Julio, Historia de Chile. El periodo parlamentario 1861-1925. Tomo I: Fundamentos histórico-culturales del parlamentarismo chileno (Santiago, Editorial Jurídica de Chile, 1974).

IbÁNÉz SANTA María, Adolfo, Herido en el ala: Estado, oligarquías y subdesarrollo. Chile 1924-1960 (Santiago, Editorial Biblioteca Americana, 2003).

Kelsen, Hans, Observaciones sobre la Constitución chilena (traducción de Joaquín García Huidobro de artículo publicado en 1926), en Anuario de Filosofía Jurídica y Social, 20 (2002), pp. 643-647.

Ley de reforma constitucional No 43, 26 de febrero de 1892.

Ley de reforma constitucional $\mathrm{N}^{\circ} 7.727,23$ de noviembre de 1943.

Ley de reforma constitucional $\mathrm{N}^{\circ} 17.284,23$ de enero de 1970 .

Ley de reforma constitucional $\mathrm{N}^{\circ} 17.398,9$ de enero de 1971.

LOEWENSTEIn, Karl, La presidencia fuera de los Estados Unidos (estudio comparativo de instituciones políticas), en Boletín del Instituto de Derecho Comparado de México, 5 (1949), pp. 15-64.

MELÉndez, Felipe, La forma de gobierno en el Chile actual: un caso de presidencialismo latinoamericano equilibrado, en Revista Republicana, 26 (2019), pp. 21-42.

-La influencia del control preventivo en el diseño normativo del régimen presidencial chileno, en Anuario Iberoamericano de Justicia Constitucional, 21 (2017), pp. 81-110.

Ministerio Del INTERIor, Actas oficiales de las sesiones celebradas por la Comisión y Subcomisiones encargadas del proyecto de nueva Constitución Politica de la República (Santiago, Imprenta Universitaria, 1925).

Nogueira, Humberto, La tipología de gobiernos presidencialistas de América Latina y gobiernos semipresidenciales en Europa, en Estudios Constitucionales, 2 (2017), pp. 15-82.

Palma, Eric, El Estado socialista según la legislación irregular de Carlos Dávila (junioseptiembre de 1932), en Estudios Constitucionales, 1 (2017), pp. 373-404. 
Ruiz-Tagle, Pablo, Cinco repúblicas y una tradición. Constitucionalismo chileno comparado (Santiago, Lom, 2016).

SCUlly, Timothy, Los partidos de centro y la evolución política chilena (Santiago, CIEPLAN - Notre Dame, 1992).

Silva Bascuñán, Alejandro, Tratado de derecho constitucional, Tomo III: La Constitución de 1925 (Santiago, Editorial Jurídica de Chile, 1963), II.

Silva Cimma, Enrique, El Tribunal Constitucional de Chile (2a ed., Santiago, Cuadernos del Tribunal Constitucional, 2008).

Soto Velasco, Sebastián, Congreso Nacional y proceso legislativo. Teoría y práctica (Santiago, Thomson Reuters, 2015).

TAPIA VAldÉs, Jorge, La técnica legislativa (Santiago, Editorial Jurídica de Chile, 1960).

Valencia Avaria, Luis, Anales de la República (2a ed., Santiago, Editorial Andrés Bello, 1986).

Valenzuela, Arturo y Wilde, Alexander, El Congreso y la redemocratización en Chile, en Alternativas, 3 (1984).

Verdugo, Mario; Pfeffer, Emilio; Nogueira, Humberto, Derecho constitucional (2a ed., Editorial Jurídica de Chile, 2005), I.

Vial Correa, Gonzalo, Decadencia, consenso y unidad nacional en 1973, en Dimensiones Históricas de Chile, 1 (1984), pp. 140-154.

ZúNigA, Francisco, Constitución y ley interpretativa. Algunas notas sobre una paradoja y peligros relativos a este tipo de ley, en Ius et Praxis, 2 (2009), pp. 255-281. 